\title{
Demographic, Bio-Psychological and Socio-Economic Factors Associated with Recidivism at a Central Prison in Zimbabwe
}

\author{
Virgininia Dube-Mawerewere $^{1}$, Gabriel Machinda Chiborise ${ }^{2}$ \\ ${ }^{1}$ University of Zimbabwe, Harare, Zimbabwe \\ ${ }^{2}$ Zimbabwe Prison and Correctional Services, Harare, Zimbabwe \\ Email:virgydube@gmail.com,gabchibs@gmail.com
}

How to cite this paper: Dube-Mawerewere, V. and Chiborise, G.M. (2017) Demographic, Bio-Psychological and Socio-Economic Factors Associated with Recidivism at a Central Prison in Zimbabwe. Open Journal of Social Sciences, 5, 35-45.

https://doi.org/10.4236/jss.2017.58003

Received: June 14, 2017

Accepted: July 31, 2017

Published: August 3, 2017

Copyright $\odot 2017$ by authors and Scientific Research Publishing Inc. This work is licensed under the Creative Commons Attribution International License (CC BY 4.0). http://creativecommons.org/licenses/by/4.0/

\begin{abstract}
The purpose of this study was to determine factors associated with recidivism at a Central Prison in Zimbabwe. A descriptive quantitative cross sectional survey was done. Purposive sampling was used to draw respondents for the study. Data were collected from 30 inmates who had been re-imprisoned. A structured interview was used to collect data. The results revealed that a confluence of complex demographic, biological, economic, social and psychological factors was responsible for occurrence of recidivating or habitual relapse into crime. A recommendation calling for the Zimbabwe Prisons and Correctional Services to introspect, redefine its operations and refocus its mandate while collaborating with other organizations to intensify rehabilitation and re-integration programmes in prisons was projected.
\end{abstract}

\section{Keywords}

Central Prison, Recidivism, Zimbabwe Prison \& Correctional Service, Factors, Bio-Psychological, Socio-Economic, Factors

\section{Introduction}

Zimbabwe Prisons and Correctional Service (ZPCS) were established in terms of Section 227 of the new Constitution of Zimbabwe. ZPCS is a paramilitary organization under the Ministry of Justice, Legal and Parliamentary Affairs and is headed by the Commissioner-General of Prisons and Correctional Service. At the time of the study, ZPCS operated in accordance with the Zimbabwe Prisons Act Chapter 7:11 of 1996, Zimbabwe Prisons (General) Regulations, Statutory Instrument 1 of 1996 and the Zimbabwe Prison Service Standing Orders [1] [2] [3]. 
The Central Prison is one of the prisons regulated by these instruments. It has a holding capacity of 1470 inmates but holds an average of up to 2000 inmates at any given time. Recidivism in prisons has seen inmates overcrowding at such institutions like the Central Prison. In 2010, 2013 and in 2016 following Presidential pardoning of more than 2000 inmates, more than 50\% filtered back into prison barely three months post release. Yet Zimbabwe Prisons and Correctional Service's mission statement borrowing from the Constitution of Zimbabwe is "to protect the society from criminal elements through the incarceration and rehabilitation of offenders for their successful reintegration into the society whilst exercising, reasonable, safe, secure and humane controp'. In line with the mission, offenders are purported to come to prisons to be rehabilitated for their successful reintegration into society. Clearly, the Zimbabwean society has failed to contain the ex-prisoners and the question is why? There is dearth of empirical evidence on demographic, bio-psychological and socio-economic factors associated with recidivism in Zimbabwe.

This study sought to initiate the understanding of variables that were associated with reoffending and consequent reincarnation of prisoners, focusing on the Central Prison in Zimbabwe. The Central Prison was chosen because of its centrality as a referral prison which received reoffenders from diverse backgrounds and different parts of the country.

\section{Methodology}

A cross sectional survey design was used for the study. Structured interviews were conducted on reoffenders serving a sentence at the time of the study. Thirty respondents were purposefully sampled for the study. Inclusion criteria for the respondents were as follows:

- The respondents were supposed to have been incarcerated before;

- They had to be 18 years and above;

- The respondents were serving a sentence at the Central Prison at the time of the study.

Recidivism was conceptualized as re-incarceration, reoffending or imprisonment of a person who was convicted before, was released from prison custody and was currently serving a sentence for yet another criminal offence.

\subsection{Ethics}

Permission to conduct the study was obtained from the Department of Research and Development (Zimbabwe Prison and Correctional Service). Other offices involved for ethical clearance included The Officer Commanding of the Central Province and the Officer in Charge of the Central Prison. Informed consent was obtained from individual respondents who participated in the study.

\subsection{Results of the Study}

The following is an account of demographic, bio-psychological and socio-eco- 
nomic factors associated with recidivism among prison inmates at a Central Prison in Zimbabwe.

\section{Demographic Characteristics of Recidivist Prison Inmates}

\subsection{Age}

Demographic factors showed that the majority of respondents $57 \%$ were in the age group of 31 years and above. Criminal behaviour and age are related in that recidivism tends to decrease with advancing years [4]. Conscious of these contrasting results, the study will imply that the age recidivism trend of the study sample tended to recidivate more as they became older at the Central Prison in Zimbabwe. Criminal behavior in the context of the study could be related to the need to meet both individual and family needs in an economically unstable environment.

\subsection{Education}

Results of this study showed that $77 \%$ had attained primary education only. This concurs with a study which pointed out that low levels of personal, educational, vocational, and financial achievement are other risk factors of recidivism [5]. In view of that assertion, the study concluded that illiteracy is a driver of recidivism among the population under study, most probably because of lack of life skills.

\subsection{Marital Status}

The study showed that the majority (57\%) were single. This is in support of a position that marital status is associated with both incidence and outcome of recidivism [6]. A conclusion can then be reached from this study that lack of responsibility associated with being single could be a driving force to the singles continuing to reoffend. In other words, marriage increased the chances of desisting from criminal behavior. Conversely, being single could then be an important lever for recidivism.

\subsection{Employment}

The study found that the majority, $67 \%$ of respondents had never been employed. With a prior criminal record, incarceration history and few skills, it is a struggle to find jobs for ex-inmates resulting in them committing further crimes [7]. The same concept could also be applied to recidivist prisoners at the Central Prison. Because of repeat offending, the respondents could have been spending much of their time in prison at the expense of gaining employment experience which could then enable them to get a job.

\subsection{Previous Convictions}

A $100 \%$ of respondents had previous convictions. These results maintain the position that people sent to prison are not deterred by imprisonment hence they continue engaging in criminal activities even upon release, thus explaining high 
recidivism rates [8]. It could also be possible that previous imprisonment had negative effects that reinforced recidivism among respondents in the study.

\subsection{Family Members with a History of Imprisonment}

Even if $83 \%$ had no close relatives ever committed to prison, this result was contrary to literature assertions that show that there is consistently a history of crime in families of inmates. The result was also undermined by the $17 \%$ who either had their father or sibling once imprisoned. A study on criminal behaviour found that familial dispositions to criminal tendencies are related to genetic, biological and socio-environmental exposure [9]. A related study also found that children of imprisoned parents are 6 times more likely to be imprisoned as well compared to children whose parents had never been incarcerated [10]. An inference can be made that reoffenders at the Central Prison could have developed criminal tendencies of their own accord and for some it could have emanated from modelling, genetic and negative environmental exposures.

\subsection{Type of Crime}

Most re-offender respondents were involved in theft, rape, assault and armed robbery. This trend is in line with a report published on international statistics on crime and justice [11]. Similar crime trends applied to the study which means that types of crime are a significant factor as drivers of recidivism in the context of the study.

\subsection{Number of Children}

$56 \%$ of the respondents had 1 (one) child each. The study showed that those who have many children do not recidivate as much as their counterparts with few children. This concurs with results of a study which demonstrated that those inmates who have children tend to exhibit a lower rate of recidivism than inmates without children [10]. The author explains that parents' incarceration affects children emotionally and behaviorally and has a bearing on the family stability and financial dynamic. This could be a similar case of responsibilities in the study context, those with fewer responsibilities can risk to engage in criminal behavior than those with more responsibility.

\subsection{Area of Origin}

Majority of the recidivists (50\%) according to results of this study came from urban areas while the rest came from rural areas, mining and farming communities. All these areas are low resource communities. A study that looked at area of origin showed risk factors to recidivism as neighborhood conditions and residential mobility [12]. The same study showed that when subjects of the trial moved to neighbourhoods with reduced poverty and reduced crime, violent crime arrests became fewer. In the study context, criminality could emanate from the rural urban migration trends in Zimbabwe that result in unemploy- 
ment. Exposure to such economic disadvantage then becomes an important lever for criminal behaviour and reoffending.

\section{Bio-Psychological Factors}

\subsection{Associated Medical Problems}

Results showed that $67 \%$ did not have associated medical problems while a collective $33 \%$ were spread over history of head trauma, epilepsy and mental illness. There is evidence that there is indeed a relationship between crime and mental malfunctioning [13]. This was confirmed by a significant $33 \%$ of neurological conditions that the respondents had. These conditions could be a contributory factor to recidivism. On the contrary, the $67 \%$ indicated that associated medical problems are not related to criminal behaviour. This means that there are other factors that could be either psychological, social or economic to account for criminal behavior.

\subsection{Feelings around Committing a Crime}

The results showed that $60 \%$ of the respondents felt angry or had anger issues that influenced their criminal behaviour. An exploration of the relatedness of emotions and criminal behavior found that anger is a constant characteristic in criminal behavior [14]. It is therefore conceivable that criminal tendencies of respondents could have been an impulse control problem whereby the inmates failed to control the anger impulse which culminated in them committing crime repeatedly. The anger could be originating from genetic, socio-environmental and unresolved psychological exposures.

\subsection{Perception of Being in Prison}

The majority $78 \%$ perceived prison as hard such that they longed to go home. A recent study found that inmates whose educational level was high perceived prison life as not difficult as compared to inmates with lower levels of education [15]. Respondents in this study had primary (lowest) level of education which could explain why they wanted to go home instead of being in prison. This is counterintuitive though since this notion of discomfort with prison should have served as a deterrent to recidivism. It could then be possible that the recidivates at the Central Prison could be finding themselves torn between two worlds, the first one being the hard prison conditions and the second being the failure to resist the impulse to commit crime. As a result, the impulse could be outweighing the prison conditions hence they continue committing crime despite negative prison conditions.

\subsection{Reasons for the Most Recent Imprisonment}

The results show that $33 \%$ were in prison for violent behaviors. The rest being nonviolent crimes. The study noted that there were several confluence factors 
leading to imprisonment, mostly revolving around violent and nonviolent crimes. In the context of the study aggressive behavior could have emanated from failure to cope in the community after discharge. Rejection by family, need for economic adjustment and lack of professional support from the prison could have resulted in the violent behavior and subsequent re-incarceration.

\subsection{Triggering Factors to Commit Crime}

The study showed that in $43 \%$ of cases, peer pressure played an important role in starting a cycle of criminal behavior. It also became apparent during the study that a collective $44 \%$ of cases bordered around spontaneity of criminal behavior where an opportunity presented itself. Commitment of crime is a combination of environmental, socioeconomic and psychological exposures [16]. The author positioned that a negative peer group advanced the cause of criminal behavior in view of contradictory factors that include both competition among group members and demonstration of solidarity. Solidarity issues could apply to Central Prison recidivates since they lived in a country that is not economically stable with resultant psychological stress and sheer lack of resources. This could be one factor leading to need for such groupings that would be necessary to commit crime effectively among recidivates.

\subsection{Challenges Faced by Respondents}

$40 \%$ of respondents were an extra financial problem back home with the other $40 \%$ indicating that family members were embarrassed with them. This phenomenon was found to be linked to lack of family support, lack of information and lack of structure prelease. Lack of follow up and unemployment were important challenges faced by inmates upon release into the community [17]. Respondents in the study faced a similar predicament when they faced hostility from family and society upon their previous release. The hostility and maltreatment is what could be an important factor in recidivating their way back to prison where they felt accepted.

\subsection{Recidivists' Management of Stressful Situations}

Results showed that $47 \%$ ignored stressful situations while $30 \%$ sought help from peers and the remaining $23 \%$ used substances for coping with stressful situations. Respondents sought help from peers who were in a similar predicament as themselves. Peers invariably ended up leading them to use substances, engaging in criminal behavior, creating yet another fertile ground for re-committing crimes. Ex-prisoners' major stressful life events revolve around economic insecurity that emanates from their record of having been previously imprisoned [18]. Employers are reluctant to engage them. Being economically insecure then directly translate and spill to other stresses like family rejection and not being able to provide for self. In such a scenario, recidivism becomes inevitable. 


\subsection{Last Discharge Circumstance}

Results showed that (37\%) of respondents completed their sentence to earn their freedom in the previous imprisonment while a cumulative 57\% either paid a fine or bail. These results show that people generally prefer to be out of custody than long-term imprisonment as evidenced by those who paid fine and bail were few than those who completed their sentences. Those who completed their sentences could have been hardened and negatively influenced by imprisonment which could then explain why those who completed sentences are the ones who committed further crimes.

\section{Socio-Economic Factors}

\subsection{Type of Family of Origin}

Results showed that the majority (47\%) came from a nuclear family, $27 \%$ were a stepchild from a nuclear family while the rest originated from extended families. The immediate family is generally considered to be a mediator between the individual and the wider society. As such the family is expected to provide the major socio-emotional environment to which a prisoner returns. Empirical evidence has positioned that successful reintegration post prison depends to a large extent upon the kind of family to which the prisoner belongs and upon its attitudes, perceptions and acceptance of him/her [19]. In the same study providing this empirical evidence, families pointed out that economic resources were a central challenge mitigating against being supportive of their inmate relative in terms of visitation and contacting the inmate while they were in prison. It is therefore possible for the study context that the families were not as supportive as would have been expected because of similar challenges. Returning to a frustrated, hostile and unreceptive family only gave a person who had been released impetus to commit further crimes.

\subsection{Interaction with Friends outside Prison}

Results showed that the majority (53\%) were involved in socially acceptable activities with peers. $27 \%$ were involved in illegal activities, $7 \%$ formed gangs to protect themselves while $13 \%$ hung around doing nothing. These results concur with the findings which showed that there was no significant relationship between peer support and recidivism in the period one to fifteen months post release from prison [20]. This means that peer support does not protect against reoffending. The majority of respondents in the study were involved with their peers but this did not prevent them from committing crimes and going back to prison. This then translates to the notion that recidivates have individual responsibility in recommitting crimes.

\subsection{Previous Employment Experience}

Results showed that the half of the respondents (50\%) had never been formerly employed. A collective $27 \%$ couldn't either hold a job or handle short term con- 
tracts. Only $23 \%$ were able to maintain a job before they were imprisoned. Formal employment history in the preceding imprisonment has been linked with less chances of recidivism. Literature has shown that inmates who were not employed before imprisonment tended to be keen to be involved in prison programs that increased their employability post incarceration [21]. This was proven to have reduced recidivism within 5 years and there was a $40 \%$ increase in their employment rate. On the other hand being previously employed had no significant effect on reoffending. In the study context the employment situation was very critical so that individuals could address personal immediate needs. If one failed to address these needs, this became a catalyst to criminal behaviour. Respondents were not privileged to participate in programs that would aid employability after release. It is also important to note that in the study context, respondents did not have collateral security to secure loans from banks for capital. Also because of lower educational levels, they could not write business proposals to secure loans from banks. This further complicated their economic predicament leaving them with crime as one of the options with which to survive.

\subsection{Family Members Affected by Their Behaviours}

Results showed that (50\%) of the respondents affected their parents and 33\% affected respondents' partners (in the study context this did not necessarily refer to the wife but anyone in an intimate relationship with the respondent) by their behaviour. Studies have posited that an area of particular concern for those reentering the prison is relationships with support systems [22]. The absence of respondents could have negatively impacted on the family structure, and their return was inevitably met with ambivalence by those who took over the role of the absent parent. In the study context, the participants could not provide psychosocial and economic support to their family hence they were shunned by their partners and family upon their return. It is also important to note that in the study context, prison and correctional facilities did not allow for conjugal rights to be fulfilled, partners felt abandoned hence getting negatively affected by the behaviours of their partners. Parents particularly faced discrimination and labelling from the communities in which they resided because their "child" had been imprisoned. The resources families were supposed to channel for their upkeep were used to travel very long distances to visit their son or partner in prison. This resulted in the shunning of the ex-prisoners leading them to be frustrated and filter back through the cracks of the prison system.

\subsection{Combined Family Income}

The results showed that $46 \%$ survived on less than $\$ 250$ per month. A study conducted about this particular phenomenon found that average earnings for people who would have been imprisoned are extremely low [23]. In Zimbabwe unlike in developed countries there are no welfare programs to contain this. This means that even if the ex-prisoners were involved in socially acceptable activi- 
ties, it was not much to sustain them. This exposed them to economic hardships that triggered a relapse. Respondents had lower levels of education and therefore had fewer rewards, were less likely to have available alternative courses of action in times of stress hence ended up engaging in criminal activity.

\section{Conclusion}

Recidivism was found to be related to demographic, psychological and socioeconomic elements. The major criminal offences were theft and rape. Unemployment and lack of family support were important levers in reoffending among respondents. It is imperative that Zimbabwe Prisons and Correctional Services make a collaborative effort with external partners in the rehabilitation and re-integration process. This partnership would foster design and implementation sustainable rehabilitation programmes that promote employability post incarceration or empower ex-prisoners to initiate viable projects.

\section{Implications of the Study}

Responsible authorities need to look for ways of breaking crime cycle. There is also need to identify and address root causes of crime together with media, faith based organizations (FBOs), Nongovernmental organizations (NGOs), criminal justice system, victims and offenders to be involved in rehabilitation and re-integration.

Policy makers should ensure there are programs for habitual offenders in prisons. Also the prison system should involve family members in rehabilitation and re-integration of offenders. Community corrections should also be revived because the inmate would have originated from the community and at the end of his term returns to the same community.

Specialist staff in the area of mental health (psychologists, psychiatrists, psychiatric nurses, occupational therapist and social workers) should be enrolled into the prison system, because a multidisciplinary approach will assist inmates with psychological challenges.

\section{Limitations of the Study}

The study was conducted at only one prison which is a prison for male inmates only. The study had a minimum sample size of thirty respondents. Results can therefore not be generalized beyond the study context. The research would need to be replicated using a wider sample and more robust quantitative and qualitative methods to have a broader perspective of both the magnitude of the problem towards developing a context specific way forward for the prison system in Zimbabwe.

\section{References}

[1] Zimbabwe (1996) Prison Act Chapter 7:11. Government Printer, Harare.

[2] Zimbabwe (1996) Prisons (General) Regulations Chapter 21. Statutory Instrument 
1. Government Printer, Harare.

[3] Zimbabwe (Undated) Prison Service Standing Orders. Government Printer, Harare.

[4] Castillo, R., William, K., Steer, J.R., Hinojosa, R.H., Horowitz, M.E., O’Neill, M.E., Reilly, E.F. and Rhodes, D.J. (2004) Measuring Recidivism: The Criminal History Computation of the Federal Sentencing Guidelines. United States Sentencing Commission.

[5] James, N. (2015) Offender Reentry: Correctional Statistics, Reintegration into the Community, and Recidivism. Congressional Research Service.

[6] Andersen, S.H., Andersen, L.H. and Skov, P.E. (2015) Effect of Marriage and Spousal Criminality on Recidivism. Journal of Marriage and Family, 77, 496-509. https://doi.org/10.1111/jomf.12176

[7] Nally, J.M., Lockwood, S., Ho, S.T. and Knutson, K. (2012) The Post-Release Employment and Recidivism among Different Types of Offenders with a Different Level of Education: A 5-Year Follow-Up Study in Indiana. Justice Policy Journal, 9, 129.

[8] Nagin, D.S., Cullen, F.T. and Jonson, C.L. (2009) Imprisonment and Reoffending. Crime and Justice, 38, 115-200. https://doi.org/10.1086/599202

[9] Mendes, D.D., Mari, J.J., Singer, M., Barros, G.M. and Mello, A.F. (2009) Study Review of Biological, Social and Environmental Factors Associated with Aggressive Behavior. Revista Brasileira de Psiquiatria, 2, S77-S85.

https://doi.org/10.1590/S1516-44462009000600006

[10] Christian, S. (2009) Children of Incarcerated Parents. Casey Family Foundation.

[11] Harrendorf, S., Heiskanen, M. and Malby, S. (2010) International Statistics on Crime and Justice. Heuni.

[12] Kling, J.R., Ludwig, J. and Katz, A.F. (2005) Neighborhood Effects on Crime for Female and Male Youth: Evidence from a Randomized Housing Voucher Experiment. The Quarterly Journal of Economic, 120, 87-130.

[13] Stevens, H. (2013) Crime and Mental Disorders. Aarhus University, Aarhus.

[14] Cassese, E. and Weber, C. (2011) Emotion, Attribution, and Attitudes toward Crime. Journal of Integrated Social Sciences, 2, 63-97.

[15] Crank, B.R. (2010) Adapting to Incarceration: Inmate Perceptions of Prison Life and Adjustment. Georgia State University, Georgia.

[16] Hateu, M.K. (2016) An Assessment of Socio-Economic Factors on Crime: A Case Study of Kaliti Correctional Administration, Ethiopia. Addis Ababa University, Addis Ababa.

[17] Grommon, E., Rydberg, J. and Bynum, T. (2012) Understanding the Challenges Facing Offenders upon Their Return to the Community: Final Report. Michigan Justice Statistics Center, Michigan.

[18] Harding, D.J., Wyse, J.J.B., Dobson, C. and Morenoff, J.D. (2014) Making Ends Meet after Prison. Journal of Policy Analysis and Management, 33, 440-470. https://doi.org/10.1002/pam.21741

[19] Naser, R.L. and Visher, C.A. (2006) Family Members' Experiences with Incarceration and Reentry. Western Criminology Review, 7, 20-31.

[20] Taylor, C. and Becker, P. (2015) Are Your Friends Crucial or Trivial? Peer Support's Effect on Recidivism. Justice Policy Journal, 12, 1-20.

[21] Bhuller, M., DahL, G.B., Løken, K.V. and Mogstad, M. (2016) Incarceration, Recidivism and Employment. University of Chicago, Chicago. 
https://doi.org/10.3386/w22648

[22] Dennison, S., Foley, D. and Stewart, A. (2005) Understanding Experiences and Needs of Families of Prisoners. Griffith University, Nathan.

[23] Western, B., Braga, A.A., Davis, J. and Sirois, C. (2014) Stress and Hardship after Prison. National Science Foundation, Cambridge.

Submit or recommend next manuscript to SCIRP and we will provide best service for you:

Accepting pre-submission inquiries through Email, Facebook, LinkedIn, Twitter, etc. A wide selection of journals (inclusive of 9 subjects, more than 200 journals) Providing 24-hour high-quality service User-friendly online submission system Fair and swift peer-review system Efficient typesetting and proofreading procedure Display of the result of downloads and visits, as well as the number of cited articles Maximum dissemination of your research work

Submit your manuscript at: http://papersubmission.scirp.org/

Or contact jss@scirp.org 